Под аркологией понимают идею о том, что путём воздвижения гиперструктур, вмещающих целый город, можно снизить негативное воздействие поселений на окружающую среду. Предполагается, что заново отстраиваемые аркологии будут способствовать лучшему планированию и использованию общественного транспорта, что позволит повысить плотность населения, избегая при этом классических проблем больших городов.

Рассмотренные идеи пространственной организации поселений лежат в основе большинства существующих концепций. Выявим их общие черты:

- Жилые, общественные, производственные и иные городские объекты связаны скоростной сетью общественного транспорта, городских коммуникаций и энергосетей;

- Город переходит из состояния совокупности отдельных зданий к одной гиперструктуре, вмещающей все функции городского организма;

- Признаётся необходимость сохранения и ревитализации природного ландшафта. Здесь речь идёт не только об оздоровлении экологии места жизни человека, но о природе как самоценности.

$$
* * *
$$

1. Бунин А.В., Саваренская Т.Ф. «Градостроительство XX века в странах капиталистического мира. Том второй» - Москва: Стройиздат, 1979;

2. Линейная модель расселения: ретроспективный анализ концепции идеального города // Витюк Е.Ю.// «Архитектон: известия вузов»№47: http://archvuz.ru/2014_3/3;

3. Градостроительные концепции конца 19-начала 20в. // «Архитектура и дизайн»: https://archidizain.blogspot.ru/2012/02/19-20.html.

\title{
Найденова И.В.
}

Преемственность процессов модернизации аграрного сектора г. Корочи в рамках концепции развития агропромышленного комплекса Белгородской области

doi: $10.18411 / s p c-28-10-2017-03$

idsp: 000001:spc-28-10-2017-03

\section{Аннотация}

В статье рассматривается динамика развития предприятий аграрного сектора Белгородской области на примере малого города Короча с момента реализации постановления администрации от 14 декабря 1999 г., задавшего направление положительной динамики в сфере сельхоз производства. Несмотря на то, что развитие агропромышленного комплекса в малых городах региона происходит неравномерно, данный процесс на этапах реализации целевых программ характеризуется схожими чертами.

Ключевые слова: агропромышленный комплекс, агрохолдинг, сельхозпредприятие

Белгородскую область можно отнести к числу наиболее активно развивающихся регионов России [3]. По итогам 2015 г. был внесен весомый вклад в объем произведенной продукции сельского хозяйства (4,3 \% и $17,7 \%$ продукции в России и Центральном Федеральном округе соответственно). Агропромышленный комплекс обеспечил около 30\% валового регионального продукта в 2015 г., что на 13\% превышает показатели 2009 г. Данные статистики подтверждают тенденции к развитию 
сельхозпроизводства в сравнении с горнодобывающей промышленностью, которая являлась главной опорой экономики области до 1999 г.

Корочанский район является территорией с исторически сформированным аграрно-индустриальным типом развития. По данным описей за 1900 г., в Корочанском уезде существовало более 50 промышленных предприятий, из них 27 предприятий пищевой промышленности, рассчитанных на оптовую торговлю, в том числе 6 медовопивоваренных заводов.

В период экономического кризиса, несмотря на финансовую поддержку администрации области, в результате физического и морального износа производственных мощностей к 1998 г. более 80\% сельхоз предприятий в регионе являлись убыточными, индекс рентабельности составлял -21\%. Ситуация начала меняться в конце 1999 г. с принятием постановления «О мерах по экономическому оздоровлению неплатежеспособных сельскохозяйственных предприятий области». Основные положения принятой концепции оздоровления представлены на рис. 1.

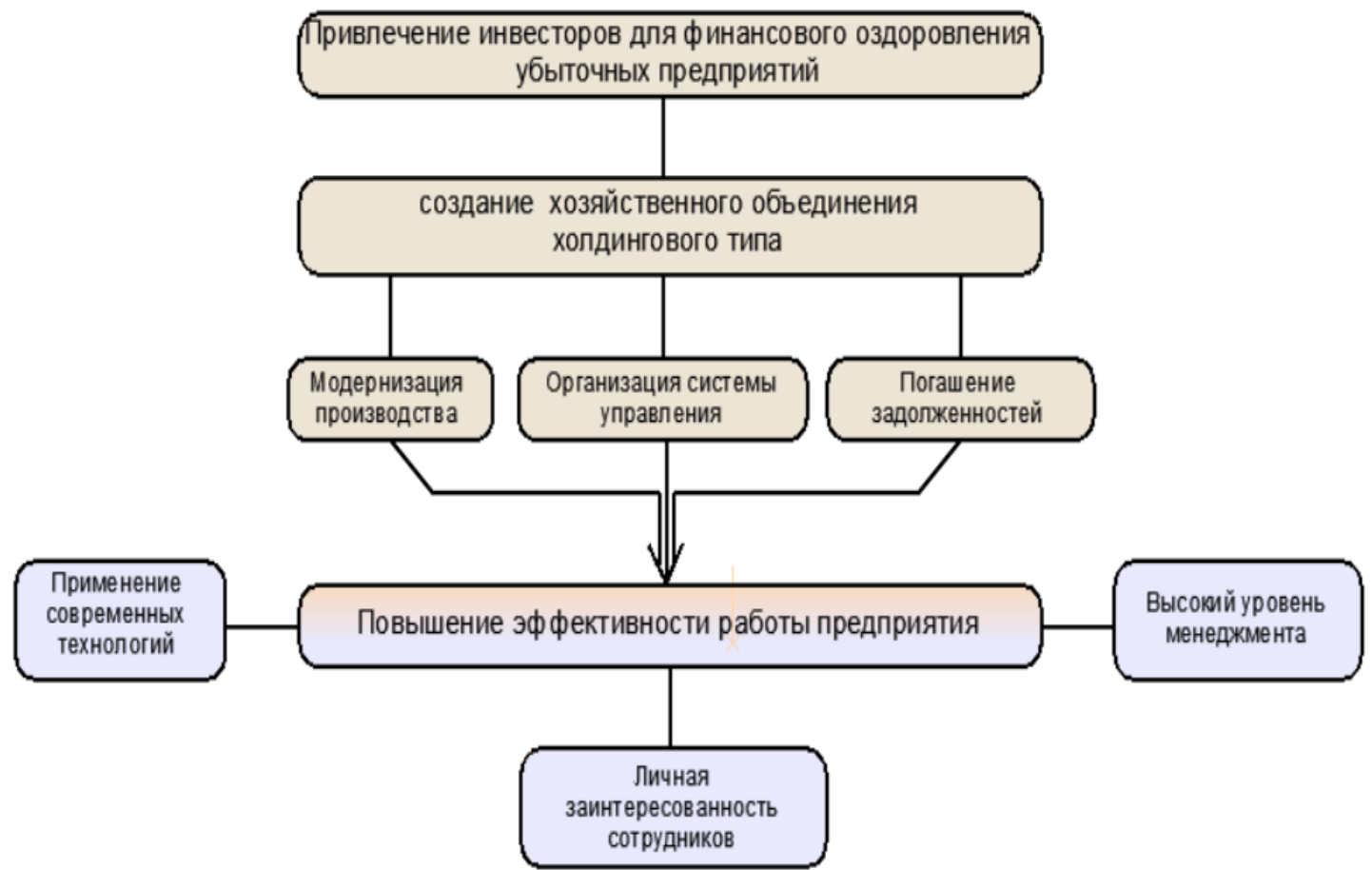

Рис. 1. Модель развития предприятий, не способных самостоятельно вести производственную деятельность, сост. И. В. Найденова

Несмотря на то, что сроки реализации постановления были установлены до 2006 г., эффективность выбранного направления в аграрном секторе была подтверждена в течение двух лет. По итогам 2000 г. индекс производства продукции сельского хозяйства составил 120,3\%. Фактически, можно назвать данный результат отправной точкой положительной динамики развития агропромышленного комплекса в регионе, которая сохраняется и в настоящее время.

Преодоление последствий экономического кризиса, как в целом по области, так и в отдельных районах, стало возможно во многом благодаря переходу от текущего и среднесрочного планирования к разработке долгосрочных стратегий собственного развития [6]. Первым толчком к кардинальным изменениям в сфере сельхоз производства стало привлечение инвесторов и создание агропромышленных объединений холдингового типа. Заданный вектор движения был поддержан в 2006 г. в рамках приоритетного национального проекта «Развитие АПК» [7]. 
В Корочанском районе был сделан упор на развитие мясного кластера (активный рост отрасли начался в 2004 г. со стартом программ мясного животноводства) и перерабатывающей промышленности. В настоящий момент в указанных отраслях осуществляют деятельность такие агрохолдинги: «Мираторг», «Агро-Белогороье», «Зеленая долина», «Русагро». На рис. 2. представлены крупные сельхоз предприятия, действующие в концепции развития агропромышленного комплекса Корочанского района, начиная с момента реализации постановления администрации от 14 дек. 1999 г.

Как видно из рис. 2, одни крупные предприятия района были созданы в период внедрения современной стратегии развития аграрного сектора, другие преодолели последствия экономического кризиса, в настоящее время они реконструированы и модернизированы под современные промышленные объекты.

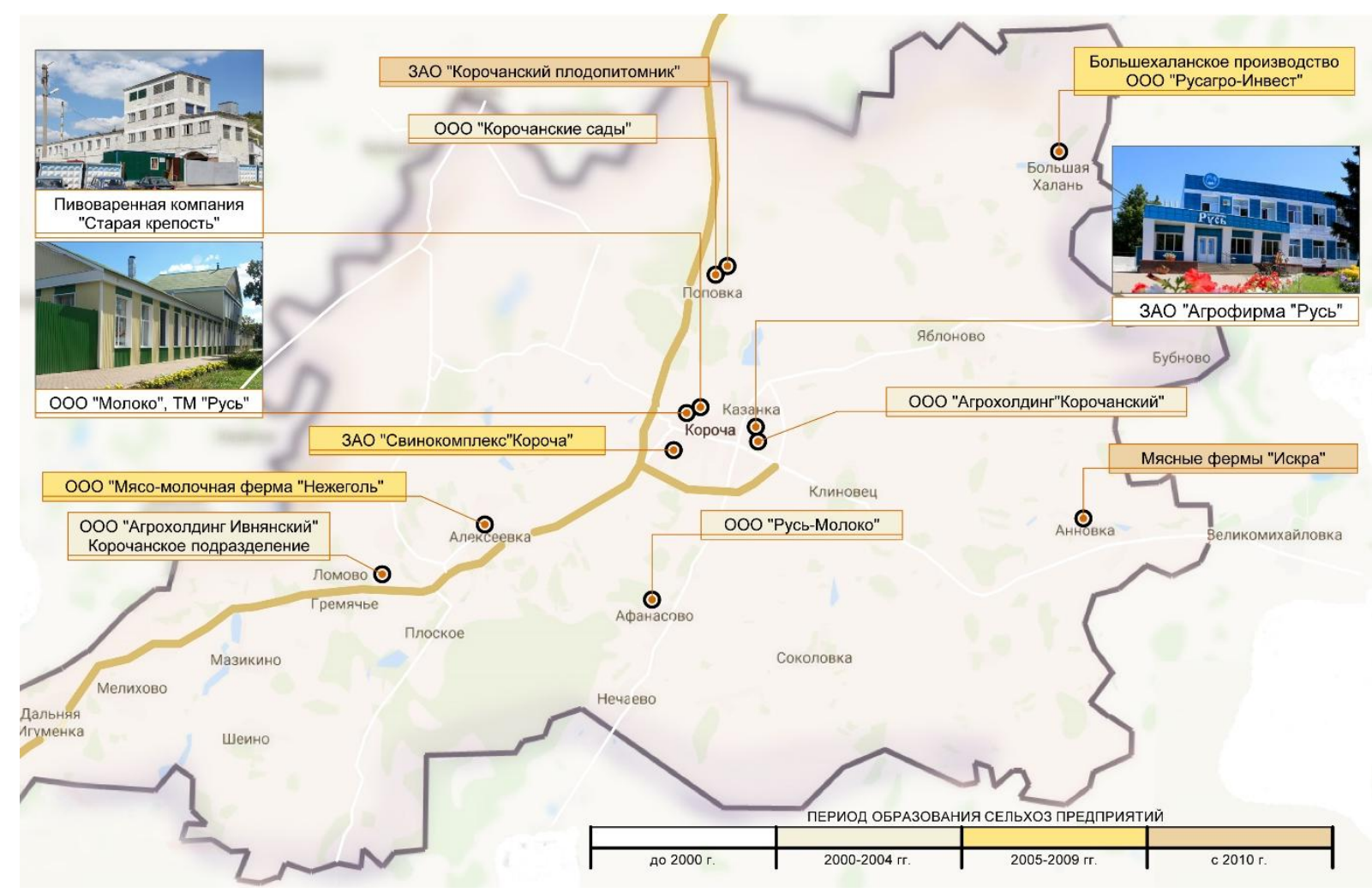

Рис. 2. Схема размещения крупные сельхоз предприятия Корочанского района. Сост. И. В. Найденова

Так, на базе бывшего Корочанского райпищекомбната, основанного в формате артели еще в 1928 г., в настоящее время функционирует ООО "Пивоваренная компания "Старая крепость", в 2017 г. преобразованное из ООО "БЕЛОГОРЬЕ" и К". В качестве инвестора выступило руководство «Кондитерской фабрики «БЕЛОГОРЬЕ», восстановление происходило в рамках принятой программы «Реконструкции и модернизации производственного комплекса ООО "БЕЛОГОРЬЕ" и К"[9]. В период с 2015 по 2020 г. планируется в 5 раз увеличить производственные мощности предприятия.

В 1954 г. в Короче был введен в эксплуатацию маслозавод, рассчитанный на переработку 3000 т. молока в год, через 10 лет здание было модернизировано с целью увеличения производственных мощностей до 30000 т. в год. Сейчас предприятие продолжает выпуск молочной продукции под торговой маркой «Русь продукт».

Птицефабрика, образованная в с. Бехтеевка в 1965 г., после ряда преобразований, в 1998 г . постановлением главы Корочанского района, была 
реорганизована в ЗАО Агрофирма «Русь». В настоящий момент представляет собой современное многоотраслевое предприятие, с входящее в состав 300 лучших сельскохозяйственных предприятий России. Специализация: производство яиц и мяса птицы, яичного порошка, подсолнечного масла холодного отжима. В 2012 г. введен в эксплуатацию собственный завод по производству комбикормов.

Еще одним историческим промышленным объектом более чем с 50-летней историей является консервный завод в с. Поповка, который не был востребован в течение последних 10 лет. В 2000 гг. был взят курс на возвращение Корочанского района в число лидеров по выращиванию плодово-ягодных культур. С 2016 г. руководством ЗАО «Корочанский плодопитомник» реализуется проект по модернизации завода в связи с растущим спросом на местную продукцию в условиях следования тенденциям импортозамещения.

Местоположение Корочи как ядра, связывающего узловые населенные пункты области между собой, обусловливает перспективы его развития[10], в т. ч. на основе формирования градообразующих предприятий областного и федерального значения. В настоящий момент, агропромышленный комплекс в целом и его ведущая отрасль, сельское хозяйство, по-прежнему, испытывают ряд проблем, в числе которых:

- довольно высокая себестоимость производства в сочетании с невысокой доходностью от реализации некоторых типов продукции (например, производство молока);

- недостаточная конкурентособность небольших предприятий в сравнении с «агрохолдингами-гигантами» в условиях монополизации торговых сетей, что влечет за собой их ликвидацию, либо интеграцию в холдинговые струкуры;

- необходимость сохранения темпов устойчивого социальноэкономического развития территорий с целью предотвращения оттока населения и закрепления на местах молодых специалистов.

В связи с ухудшением экологического состояния природной среды[11], современный подход к решению вышеуказанных проблем должен базироваться на детальном анализе накопленного отечественного и зарубежного опыта в вопросах развития аграрного сектора, особое внимание следует уделить процессам экологизации и биологизации производства на основе применения передовых технологий в растениеводстве, животноводстве, пищевой промышленности[1] с целью сохранения природного потенциала сельхоз угодий и снижения негативного влияния производственной деятельности на окружающую среду.

$$
* * *
$$

1. Об утверждении государственной программы Белгородской области "Развитие сельского хозяйства и рыбоводства в Белгородской области на 2014-2020 годы" (с изменениями на 20.02.2017) [Электронный ресурс] : Постановление Правительства Белгородской области от 28 октября 2013 года №439-пп // 2005-2017. - Режим доступа: http://docs.cntd.ru/document/412303790. - 14.06.2017.

2. О мерах по экономическому оздоровлению неплатежеспособных сельскохозяйственных предприятий области [Электронный ресурс] : Постановление от 14 декабря 1999 года. - 1998-2018. - Режим доступа: http://docs.pravo.ru/document/view/13505874. - 14.06.2017.

3. Перькова М.В. Особенности планировочной структуры и перспективы развития городов с преобладанием горнодобывающей промышленности / М.В. Перькова, И.В. Найденова // Тенденции развития науки и образования: сб. науч. тр., по материалам XXI международной науч.- 
практической конференции 31 января 2017 г. - Ч. 4. - С. 31 - 35. - Самара: Изд-во НИЦ «ЛЖурнал», 2017 - 36 с.

4. Селюкова И. На пути к триллиону: Как белгородские аграрии планируют накормить страну / Ирина Селюкова // Белгородские известия. - 2016. - 24 сент. - С. 2.

5. Шедий, Е.Г. Агропромышленные холдинги Белгородской области. Практика формирования и эффективность функционирования наиболее крупных агрохолдингов (на примере Белгородской области) [Электронный ресурс] / Е. Г. Шедий // Российское предпринимательство. - 2011. - С. $177-$ 180. - №1(2) (Экономика и экономические науки). - Научная электронная библиотека "КиберЛенинка". - 2011-2017. - Режим доступа: https:/cyberleninka.ru/article/n/agropromyshlennyeh... - 14.06.2017.

6. Ращенко А.В., Перькова М.В. Проблема развития общественных пространств в малых городах. Вестник БГТУ им. В.Г. Шухова. - 2015. - №1. - С.61-64.

7. Историческая справка [Электронный ресурс] : Официальный сайт органов местного самоуправления муниципального района "Корочанский район" Белгородской области. - 20092013.- Режим доступа: http://www.korocha.ru/istoricheskaya_spravka. - 13.06.2017.

8. Козлова Н. На корочанском консервном заводе будут выпускать тыквенный сок [Электронный ресурс] / Наталия Козлова // Белпресса. - 2016. - 10 июня. - Режим доступа: https://www.belpressa.ru/news/news/na-korochanskom-konservnom-zavode-budut-vypuskat-. tykvennyjsok13501/. - 13.06.2017.

9. История предприятия [Электронный ресурс] : офиц. сайт ООО «Пивоваренная компания «Старая крепость». - 2015. - Режим доступа: http://www.starayakrepost31.ru/o-nas/istoriya-predpriyatiya/. 16.06.2017.

10. Перькова М.В. Формирование линейно-узловой структуры расселения. Вестник БГТУ им. В.Г. Шухова. - 2017. - №2. - С.120-125.

11. Перькова М.В., Ладик Е.И. Формирование структуры туристско-рекреационных территорий Белгородской области с учетом региональных особенностей. Архитектура и строительство России. - 2017. - № 1 (221). - С. 85-92.

\section{Пешкова Д.А. \\ Выявление проблем типологического разнообразия городского жилья для людей пенсионного возраста}

СамГТУ

(Россия, Самара)

doi: $10.18411 / s p c-28-10-2017-04$

idsp: 000001:spc-28-10-2017-04

\section{Аннотация}

В статье рассмотрены проблемы старения населения, демографическая ситуация в России нехватки жилья для престарелых. Рассмотрены варианты проблем решения расселения людей «третьего возраста»

Ключевые слова: пожилые люди, дома престарелых.

\section{Abstract}

The article considers the problems of population aging, the demographic situation in Russia, the shortage of housing for the elderly. The variants of the problems of solving the settlement of people of the "third age"

Key words: elderly people, nursing homes.

С 1960-х годов, в странах западной Европы, США и Австралии был повышенный интерес и устойчивый рост строительства зданий, для пожилых людей, в том числе жилья для престарелых, центров круглосуточного ухода и опеки за пенсионерами. 